\title{
Stochastic Decision Support Models and Optimal Stopping Rules in a New Product Lifetime Testing
}

\author{
Nicholas A. Nechval and Maris Purgailis \\ University of Latvia \\ Latvia
}

\section{Introduction}

The theory of stopping rules has its roots in the study of the optimality properties of the sequential probability ratio test of Wald and Wolfowitz (1948) and Arrow, Blackwell and Girshick (1949). The essential idea in both of these papers was to create a formal Bayes problem.

The formal Bayes problem is what we would now call an optimal stopping problem. A decision maker observes an adapted sequence $\left\{R_{n}, f_{n}, n \geq I\right\}$, with $E\left\{\left|R_{n}\right|\right\}<\infty$ for all $n$, where $f_{n}$ denotes the $\sigma$-algebra generated by a sequence of rewards $R_{1}, \ldots, R_{n}$. At each time $\mathrm{n}$ a choice is to be made, to stop sampling and collect the currently available reward, $\mathrm{R}_{\mathrm{n}}$, or continue sampling in the expectation of collecting a larger reward in the future. An optimal stopping rule $\mathrm{N}$ is one that maximizes the expected reward, $\mathrm{E}\left\{\mathrm{R}_{\mathrm{n}}\right\}$. The key to finding an optimal or close to optimal stopping rule is the family of equations

$$
Z_{n}=\max \left(R_{n}, E\left\{Z_{n+1} \mid f_{n}\right\}\right), \quad n=1,2, \ldots .
$$

The informal interpretation of $Z_{n}$, is that it is the most one can expect to win if one has already reached stage $n$; and equations (1) say that this quantity is the maximum of what one can win by stopping at the nth stage and what one can expect to win by taking at least one more observation and proceeding optimally thereafter. The plausible candidate for an optimal rule is to stop with

$$
\mathrm{N}=\min \left\{\mathrm{n}: \mathrm{R}_{\mathrm{n}} \geq \mathrm{E}\left\{\mathrm{Z}_{\mathrm{n}+1} \mid f_{\mathrm{n}}\right\}\right\},
$$

that is, stop as soon as the current reward is at least as large as the most that one can expect to win by continuing. Equations (1) show that $\left\{Z_{n}, f_{n}\right\}$ is a supermartingale, while $\left\{Z_{\min (\mathrm{N}, \mathrm{n})}, \mathrm{F}_{\mathrm{n}}\right\}$, is a martingale. The equations do not have a unique solution, but in the case where the index $n$ is bounded, say $1 \leq n \leq m$ for some given value of $m$, the solution of interest satisfies $Z_{\mathrm{m}}=\mathrm{R}_{\mathrm{m}}$. Hence (1) can be solved and the optimal stopping rule can be found by "backward induction". The general strategy of optimal stopping theory is to 
approximate the case where no bound $\mathrm{m}$ exists by first imposing such a bound, solving the bounded problem and then letting $\mathrm{m} \rightarrow \infty$. For reviews of the many variations on this problem and the extensive related literature, see Freeman (1983), Petrucelli (1988) and Samuels (1991).

For illustration of the stopping problem, consider the Bayesian sequential estimation problem of a binomial parameter under quadratic loss and constant observation cost. Suppose that the unknown binomial parameter $\mathrm{p}$ is assigned a beta prior distribution with integer parameters $(a, b)$ so that

$$
\pi(\mathrm{p} \mid \mathrm{a}, \mathrm{b})=\frac{(\mathrm{b}-1) !}{(\mathrm{a}-1) !(\mathrm{b}-\mathrm{a}-1) !} \mathrm{p}^{\mathrm{a}-1}(1-\mathrm{p})^{\mathrm{b}-\mathrm{a}-1}, \quad 0<\mathrm{p}<1
$$

The posterior distribution of $\mathrm{p}$ having observed s successes in $n$ trials is simply $\pi(p ; s+a, n+b)$ (Raiffa and Schlaifer, 1968); hence the result of sampling may be represented as a plot of $s+a$ against $n+b$ which stops when the stopping boundary is reached. If $a=1, b=2$, the uniform prior, is taken as the origin, sample paths for any other proper prior will start at the point $(a-1, b-2)$. Consequently stopping boundaries will be obtained using the uniform prior.

Suppose that the loss in estimating p by $d$ is $\vartheta(p-d)^{2}$ where $\vartheta$ is a constant giving loss in terms of cost. Then the Bayes estimator is the current prior mean $(s+1) /(n+2)$ and the Bayes risk is

$$
\mathrm{B}(\mathrm{s}, \mathrm{n})=\frac{\vartheta(\mathrm{s}+1)(\mathrm{n}-\mathrm{s}+1)}{(\mathrm{n}+2)^{2}(\mathrm{n}+3)}
$$

At a point $(s, n)$ let $D(s, n)$ be the risk of taking one further observation at a cost $c$ and $M(s, n)$ be the minimum risk, then the dynamic programming equations giving the partition of the $(\mathrm{s}, \mathrm{n})$ plane into stopping and continuation points are

where

$$
M(s, n)=\min \{B(s, n), D(s, n)\},
$$

$$
D(s, n)=c+\frac{s+1}{n+2} M(s+1, n+1)+\frac{n-s+1}{n+2} M(s, n+1) .
$$

The equations are similar to those of Lindley and Barnett (1965) and Freeman (1970, 1972, 1973). The optimal decision at each point is obtained by working back from a maximum sample size, which is approximately $[(1 / 2) \sqrt{\vartheta / c}]-2$. A suboptimal stopping point $(s, n)$ is defined as a first stopping point for fixed $s$ if $(s, n-1)$ is a continuation point, in this case

$$
\begin{aligned}
& D(s, n-1)=c+\frac{s+1}{n+1} M(s+1, n)+\frac{n-s}{n+1} B(s, n) \\
& \leq c+\frac{s+1}{n+1} B(s+1, n)+\frac{n-s}{n+1} B(s, n)=D^{\bullet}(s, n-1) .
\end{aligned}
$$


A lower bound for the sample size $n$ above may now be found from (7) by setting $B(s, n-1) \geq$ $\mathrm{D}^{\bullet}(\mathrm{s}, \mathrm{n}-1)$. This leads to

$$
[(\mathrm{n}+2)(\mathrm{n}+1)]^{2} \leq(\vartheta / \mathrm{c})(\mathrm{s}+1)(\mathrm{n}-\mathrm{s}) .
$$

The optimal stopping boundary starts at $\mathrm{s}=0$ and $\mathrm{n}$, and from (8) it may be shown that this sample size is at least $\left[(\vartheta / c)^{1 / 3}\right]-3$.

The approximate design obtained by (8) will be termed a one step ahead design. Both designs will obviously stop at the same maximum number of observations $\mathrm{N}$, and will give the same decision after $(\mathrm{N}-1)$ observations. The one step ahead design gives stopping boundaries, which will lie inside those of the optimal. The one step ahead design is similar to the modified Bayes rule of Amster (1963) and has been used by El-Sayyad and Freeman (1973) to estimate a Poisson process rate.

The present research investigates the frequentist (non-Bayesian) stopping rules. In this paper, stopping rules in fixed-sample testing as well as in sequential-sample testing are discussed.

\section{Assumptions and Cost Functions in Fixed-Sample Testing}

Let $c_{1}$ be the cost per hour of conducting the test, $c_{2}$ be the total cost of redesign (including the time required to implement it). The cost of redesign $c_{2}$ is undoubtedly the most difficult to estimate. This cost is to include whatever redesigns are necessary to make the probability of failure on rerun negligible. To simplify the mathematics, it is assumed that unnecessary design changes, caused by incorrectly abandoning the test, will also have a beneficial effect on performance. This assumption appears warranted for many electronic and mechanical systems, where the introduction of redundancies, higher-quality components, etc., can always be expected to improve reliability.

It will be assumed in this section that the times of interest to the decision maker are restricted to those where a failure has just occurred.

Let $X_{1} \leq X_{2} \leq \ldots \leq X_{r}$ be the first $r$ ordered past observations with lifetime distribution $f(x \mid \theta)$ from a sample of size $n$. Let $\hat{\theta}$ be the maximum-likelihood estimate of $\theta$ based upon the first $r$ order statistics $\left(X_{1}, \ldots, X_{r}\right) \equiv X^{r}$. Let $g\left(x_{1}, x_{2}, \ldots, x_{r} \mid \theta\right)$ be the joint density of the $r$ observations, $g\left(x_{1}, x_{2}, \ldots, x_{r}, x_{s} \mid \theta\right)$ be the joint density of the first $r$ and sth order statistics $(s>r)$ and $f\left(x_{s} \mid x^{r}, \theta\right)$ be the conditional density of the sth order statistic. If $\tau_{0}$ is the life specified as acceptable and the product will be accepted if a random sample of $\mathrm{n}$ items shows (s-1) or fewer failures in performance testing, then the probability of passing the test after $x_{r}$ has been observed may be estimated as

$$
\widehat{\mathrm{p}}_{\text {pas }}=\int_{\tau_{0}}^{\infty} \mathrm{f}\left(\mathrm{x}_{\mathrm{s}} \mid \mathrm{x}^{\mathrm{r}}, \hat{\theta}\right) \mathrm{dx} \mathrm{x}_{\mathrm{s}}
$$

where

$$
f\left(x_{s} \mid x^{r}, \hat{\theta}\right)=\frac{g\left(x_{1}, \ldots, x_{r}, x_{s} \mid \hat{\theta}\right)}{g\left(x_{1}, \ldots, x_{r} \mid \hat{\theta}\right)}
$$


The cost of abandoning the test is

$$
\mathrm{c}_{\text {abandoning }}=\mathrm{c}_{1} \tau_{0}+\mathrm{c}_{2}
$$

The estimated cost of continuation of the test is given by

$$
\begin{gathered}
\widehat{c}_{\text {continuing }}=\int_{\mathrm{x}_{\mathrm{r}}}^{\tau_{0}}\left[\mathrm{c}_{1}\left(\mathrm{x}_{\mathrm{s}}-\mathrm{x}_{\mathrm{r}}\right)+\mathrm{c}_{1} \tau_{0}+\mathrm{c}_{2}\right] \mathrm{f}\left(\mathrm{x}_{\mathrm{s}} \mid \mathrm{x}^{\mathrm{r}}, \hat{\theta}\right) \mathrm{d} \mathrm{x}_{\mathrm{s}}+\int_{\tau_{0}}^{\infty} \mathrm{c}_{1}\left(\tau_{0}-\mathrm{x}_{\mathrm{r}}\right) \mathrm{f}\left(\mathrm{x}_{\mathrm{s}} \mid \mathrm{x}^{\mathrm{r}}, \hat{\theta}\right) \mathrm{d} \mathrm{x}_{\mathrm{s}} \\
=\mathrm{c}_{1} \int_{\mathrm{x}_{\mathrm{r}}}^{\tau_{0}} \mathrm{x}_{\mathrm{s}} \mathrm{f}\left(\mathrm{x}_{\mathrm{s}} \mid \mathrm{x}^{\mathrm{r}}, \hat{\theta}\right) \mathrm{dx_{ \textrm {s } }}+\left(1-\hat{\mathrm{p}}_{\mathrm{pas}}\right)\left[\mathrm{c}_{1}\left(\tau_{0}-\mathrm{x}_{\mathrm{r}}\right)+\mathrm{c}_{2}\right]+\hat{\mathrm{p}}_{\mathrm{pas}}\left[\mathrm{c}_{1}\left(\tau_{0}-\mathrm{x}_{\mathrm{r}}\right)\right] \\
=\mathrm{c}_{1} \int_{\mathrm{x}_{\mathrm{r}}}^{\tau_{0}} \mathrm{x}_{\mathrm{s}} \mathrm{f}\left(\mathrm{x}_{\mathrm{s}} \mid \mathrm{x}^{\mathrm{r}}, \hat{\theta}\right) \mathrm{dx_{ \textrm {s } }}+\mathrm{c}_{1} \tau_{0}+\mathrm{c}_{2}-\mathrm{c}_{1} \mathrm{x}_{\mathrm{r}}-\hat{\mathrm{p}}_{\mathrm{pas}} \mathrm{c}_{2} .
\end{gathered}
$$

\section{Stopping Rule in Fixed-Sample Testing}

The decision rule will be based on the relative magnitude of $c_{\text {abandoning }}$ and $\widehat{c}_{\text {continuing }}$. The simplest rule would be:

If $\widehat{\mathrm{c}}_{\text {continuing }}<\mathrm{c}_{\text {abandoning }}$, i.e., if

$$
\int_{x_{r}}^{\tau_{0}} x_{s} f\left(x_{s} \mid x^{r}, \hat{\theta}\right) d x_{s}<x_{r}+\hat{p}_{p a s} \frac{c_{2}}{c_{1}},
$$

continue the present test;

If $\widehat{c}_{\text {continuing }} \geq \mathrm{c}_{\text {abandoning }}$, i.e., if

$$
\int_{x_{r}}^{\tau_{0}} x_{s} f\left(x_{s} \mid x^{r}, \widehat{\theta}\right) d x_{s} \geq x_{r}+\hat{p}_{\text {pas }} \frac{c_{2}}{c_{1}}
$$

abandon the present test and initiate a redesign.

\section{Estimation of the Probability of Passing the Fixed-sample Test}

Evaluation of the cost functions for the lifetime-testing model requires, even for relatively simple probability distributions, the evaluation of some complicated integrals that cannot always be obtained in closed form. For example, using the one-parameter exponential model for lifetime distribution, we have 


$$
\begin{gathered}
f(x \mid \sigma)=\frac{1}{\sigma} \exp \left(-\frac{x}{\sigma}\right), x \geq 0, \\
F(x \mid \sigma)=1-\exp \left(-\frac{x}{\sigma}\right) .
\end{gathered}
$$

Therefore,

$$
\begin{aligned}
& \mathrm{g}\left(\mathrm{x}_{1}, \ldots, \mathrm{x}_{\mathrm{r}} \mid \sigma\right)=\frac{\mathrm{n} !}{(\mathrm{n}-\mathrm{k}) !} \frac{1}{\sigma^{\mathrm{r}}} \exp \left(-\sum_{\mathrm{i}=1}^{\mathrm{r}} \frac{\mathrm{x}_{\mathrm{i}}}{\sigma}\right)\left[\exp \left(-\frac{\mathrm{x}_{\mathrm{r}}}{\sigma}\right)\right]^{\mathrm{n}-\mathrm{r}} ; \\
& \mathrm{g}\left(\mathrm{x}_{1}, \ldots, \mathrm{x}_{\mathrm{r}}, \mathrm{x}_{\mathrm{s}} \mid \sigma\right)= \frac{\mathrm{n} !}{(\mathrm{s}-\mathrm{r}-1) !(\mathrm{n}-\mathrm{s}) !} \frac{1}{\sigma^{\mathrm{r}+1}}\left[\exp \left(-\frac{\mathrm{x}_{\mathrm{r}}}{\sigma}\right)-\exp \left(-\frac{\mathrm{x}_{\mathrm{s}}}{\sigma}\right)\right]^{\mathrm{s}-\mathrm{r}-1} \\
& \times \exp \left(-\sum_{\mathrm{i}=1}^{\mathrm{r}} \frac{\mathrm{x}_{\mathrm{i}}}{\sigma}\right)\left[\exp \left(-\frac{\mathrm{x}_{\mathrm{s}}}{\sigma}\right)\right]^{\mathrm{n}-\mathrm{s}+1} .
\end{aligned}
$$

The maximum likelihood estimate for $\sigma$ is

$$
\hat{\sigma}=\frac{\sum_{i=1}^{r} x_{i}+(n-r) x_{r}}{r} .
$$

Replacing $\sigma$ by $\hat{\sigma}$ in the density functions and simplifying, we obtain

$$
\hat{\mathrm{p}}_{\mathrm{pas}}=\int_{\tau_{0}}^{\infty} \frac{(\mathrm{n}-\mathrm{r}) !}{(\mathrm{s}-\mathrm{r}-1) !(\mathrm{n}-\mathrm{s}) !} \frac{\left[\exp \left(-\frac{\mathrm{x}_{\mathrm{r}}}{\hat{\sigma}}\right)-\exp \left(-\frac{\mathrm{x}_{\mathrm{s}}}{\hat{\sigma}}\right)\right]^{\mathrm{s}-\mathrm{r}-1}}{\left[\exp \left(-\frac{\mathrm{x}_{\mathrm{r}}}{\hat{\sigma}}\right)\right]^{\mathrm{n}-\mathrm{r}}} \frac{1}{\hat{\sigma}}\left[\exp \left(-\frac{\mathrm{x}_{\mathrm{s}}}{\hat{\sigma}}\right)\right]^{\mathrm{n}-\mathrm{s}+1} \mathrm{dx} \mathrm{x}_{\mathrm{s}} .
$$

If we write

$$
\left[\exp \left(-\frac{x_{r}}{\hat{\sigma}}\right)\right]^{n-r}=\left[\exp \left(-\frac{x_{r}}{\hat{\sigma}}\right)\right]^{s-r-1}\left[\exp \left(-\frac{x_{r}}{\hat{\sigma}}\right)\right]^{n-s+1},
$$

then it is clear that

$$
\hat{\mathrm{p}}_{\mathrm{pas}}=\int_{\tau_{0}}^{\infty} \frac{(\mathrm{n}-\mathrm{r}) !}{(\mathrm{s}-\mathrm{r}-1) !(\mathrm{n}-\mathrm{s}) !} \frac{1}{\hat{\sigma}}\left[1-\frac{\exp \left(-\frac{\mathrm{x}_{\mathrm{s}}}{\hat{\sigma}}\right)}{\exp \left(-\frac{\mathrm{x}_{\mathrm{r}}}{\hat{\sigma}}\right)}\right]^{\mathrm{s}-\mathrm{r}-1}\left[\frac{\exp \left(-\frac{\mathrm{x}_{\mathrm{s}}}{\hat{\sigma}}\right)}{\exp \left(-\frac{\mathrm{x}_{\mathrm{r}}}{\hat{\sigma}}\right)}\right]^{\mathrm{n}-\mathrm{s}+1} \mathrm{dx} .
$$


The change of variable

$$
\mathrm{v}=\frac{\exp \left(-\frac{\mathrm{x}_{\mathrm{s}}}{\hat{\sigma}}\right)}{\exp \left(-\frac{\mathrm{x}_{\mathrm{r}}}{\hat{\sigma}}\right)}
$$

leads to

$$
\hat{\mathrm{p}}_{\mathrm{pas}}=\int_{0}^{\exp \left(-\frac{\tau_{0}-\mathrm{x}_{\mathrm{r}}}{\hat{\sigma}}\right)} \frac{(\mathrm{n}-\mathrm{r}) !}{(\mathrm{s}-\mathrm{r}-1) !(\mathrm{n}-\mathrm{s}) !} \mathrm{v}^{\mathrm{n}-\mathrm{s}}(1-\mathrm{v})^{\mathrm{s}-\mathrm{r}-1} \mathrm{dv}
$$

Thus, $\hat{\mathrm{p}}_{\mathrm{pas}}$ is equivalent to the cumulative beta distribution with parameters $(\mathrm{n}-\mathrm{s}+1, \mathrm{~s}-\mathrm{r})$. The situation for the Weibull distribution,

$$
f(x \mid \sigma, \delta)=\frac{\delta}{\sigma} x^{\delta-1} \exp \left(-\frac{x^{\delta}}{\sigma}\right), x \geq 0 ; F(x \mid \sigma, \delta)=1-\exp \left(-\frac{x^{\delta}}{\sigma}\right)
$$

is much the same, except that we make the change of variable

$$
\mathrm{v}=\frac{\exp \left(-\frac{x_{\mathrm{s}}^{\widehat{\delta}}}{\widehat{\sigma}}\right)}{\exp \left(-\frac{x_{\mathrm{r}}^{\widehat{\delta}}}{\widehat{\sigma}}\right)}
$$

The maximum likelihood estimates $\hat{\sigma}$ and $\hat{\delta}$ of the parameters $\sigma$ and $\delta$, respectively, required in (26), can only be obtained by iterative methods. The appropriate likelihood equations for $X_{1}, \ldots, X_{r}$ are

$$
\begin{gathered}
\frac{\partial \mathrm{L}}{\partial \sigma}=0=-\frac{\mathrm{r}}{\sigma}+\frac{1}{\sigma^{2}}\left[\sum_{\mathrm{i}=1}^{\mathrm{r}} \mathrm{x}_{\mathrm{i}}^{\delta}+(\mathrm{n}-\mathrm{r}) \mathrm{x}_{\mathrm{r}}^{\delta}\right] \\
\frac{\partial \mathrm{L}}{\partial \delta}=0=\frac{\mathrm{r}}{\delta}+\sum_{\mathrm{i}=1}^{\mathrm{r}} \mathrm{x}_{\mathrm{i}}-\frac{1}{\sigma}\left[\sum_{\mathrm{i}=1}^{\mathrm{r}} \mathrm{x}_{\mathrm{i}}^{\delta} \ln \mathrm{x}_{\mathrm{i}}+(\mathrm{n}-\mathrm{r}) \mathrm{x}_{\mathrm{r}}^{\delta} \ln \mathrm{x}_{\mathrm{r}}\right]
\end{gathered}
$$

Now $\widehat{\sigma}$ and $\widehat{\delta}$ can be found from solution of

$$
\widehat{\sigma}=\frac{\sum_{i=1}^{r} x_{i}^{\widehat{\delta}}+(n-r) x_{r}^{\widehat{\delta}}}{r}
$$


and

$$
\widehat{\delta}=\left[\left(\sum_{i=1}^{r} x_{i}^{\widehat{\delta}} \ln x_{i}+(n-r) x_{r}^{\widehat{\delta}} \ln x_{r}\right)\left(\sum_{i=1}^{r} x_{i}^{\widehat{\delta}}+(n-r) x_{r}^{\widehat{\delta}}\right)^{-1}-\frac{1}{r} \sum_{i=1}^{r} \ln x_{i}\right]^{-1} .
$$

The method described above is quite general and works well for a1l closed-form or tabulated cumulative distribution functions, so that numerical integration techniques are not needed for calculating $\hat{\mathrm{p}}_{\text {pas }}$. It is easy to see that the general case would involve a change of variable

$$
\mathrm{v}=\frac{1-\mathrm{F}\left(\mathrm{x}_{\mathrm{s}} \mid \widehat{\theta}\right)}{1-\mathrm{F}\left(\mathrm{x}_{\mathrm{r}} \mid \hat{\theta}\right)}
$$

where, of course, $x_{r}$ is a constant.

\subsection{Statistical Inferences for Future Order Statistics in the Same Sample}

If we deal with small size $\mathrm{n}$ of the fixed sample for testing and wish to find the conditional distribution of the sth order statistic to obtain the probability of passing the test after $x_{r}$ has been observed, then it may be suitable the following results.

Theorem 1 (Predictive distribution of the sth order statistic $X_{s}$ on the basis of the past rth order statistic $X_{r}$ from the exponential distribution of the same sample). Let $X_{1} \leq X_{2} \leq \ldots \leq X_{r}$ be the first $r$ ordered past observations from a sample of size $n$ from the exponential distribution with the probability density function (PDF) (15), which is characterized by the scale parameter $\sigma$. It is assumed that the parameter $\sigma$ is unknown. Then the predictive probability density function of the sth order statistic $X_{s}$ may be obtained on the basis of the rth order statistic $X_{r}$ $(\mathrm{r}<\mathrm{s} \leq \mathrm{n})$ from the same sample as

$$
\begin{aligned}
\tilde{f}\left(x_{s} \mid x_{r}\right)= & \frac{1}{B(s-r, n-s+1) B(r, n-r+1)} \sum_{j=0}^{s-r-1} \sum_{i=0}^{r-1}(-1)^{i+j}\left(\begin{array}{c}
s-r-1 \\
j
\end{array}\right)\left(\begin{array}{c}
r-1 \\
i
\end{array}\right) \\
& \times \frac{1}{\left[w_{s}(n-s+1+j)+(n-r+1+i)\right]^{2}} \frac{1}{x_{r}}, \quad w_{s}>0,
\end{aligned}
$$

where

$$
\mathrm{W}_{\mathrm{s}}=\frac{\mathrm{X}_{\mathrm{s}}-\mathrm{X}_{\mathrm{r}}}{\mathrm{X}_{\mathrm{r}}}
$$

Proof. It follows readily from standard theory of order statistics (see, for example, Kendall and Stuart (1969)) that the joint distribution of $X_{r}, X_{s}(s>r)$ is given by

$$
f\left(x_{r}, x_{s} \mid \sigma\right) d x_{r} d x_{s}=\frac{1}{B(r, s-r) B(s, n-s+1)}
$$




$$
\times\left[\mathrm{F}\left(\mathrm{x}_{\mathrm{r}} \mid \sigma\right)\right]^{\mathrm{r}-1}\left[\mathrm{~F}\left(\mathrm{x}_{\mathrm{s}} \mid \sigma\right)-\mathrm{F}\left(\mathrm{x}_{\mathrm{r}} \mid \sigma\right)\right]^{\mathrm{s}-\mathrm{r}-1}\left[1-\mathrm{F}\left(\mathrm{x}_{\mathrm{s}} \mid \sigma\right)\right]^{\mathrm{n}-\mathrm{s}} \mathrm{dF}\left(\mathrm{x}_{\mathrm{r}} \mid \sigma\right) \mathrm{dF}\left(\mathrm{x}_{\mathrm{s}} \mid \sigma\right),
$$

Making the transformation $\mathrm{z}=\mathrm{x}_{\mathrm{s}}-\mathrm{x}_{\mathrm{r}}, \mathrm{x}_{\mathrm{r}}=\mathrm{x}_{\mathrm{r}}$, and integrating out $\mathrm{x}_{\mathrm{r}}$, we find the density of $\mathrm{z}$ as the beta density

$$
\mathrm{f}(\mathrm{z} \mid \sigma)=\frac{1}{\mathrm{~B}(\mathrm{~s}-\mathrm{r}, \mathrm{n}-\mathrm{s}+1)}[\exp (-\mathrm{z} / \sigma)]^{\mathrm{n}-\mathrm{s}+1}[1-\exp (-\mathrm{z} / \sigma)]^{\mathrm{s}-\mathrm{r}-1} \frac{1}{\sigma} .
$$

The distribution of $X_{r}$ is

$$
f\left(x_{r} \mid \sigma\right) d x_{r}=\frac{1}{B(r, n-r+1)}\left[F\left(x_{r} \mid \sigma\right)\right]^{r-1}\left[1-F\left(x_{r} \mid \sigma\right)\right]^{n-r} d F\left(x_{r} \mid \sigma\right)
$$

and since $Z, X_{r}$ are independent, we have the joint density of $Z$ and $X_{r}$ as

$$
\begin{gathered}
f\left(z, x_{r} \mid \sigma\right)=\frac{1}{B(r, s-r) B(s, n-s+1)}[\exp (-z / \sigma)]^{n-s+1}[1-\exp (-z / \sigma)]^{s-r-1} \\
\quad \times\left[1-\exp \left(-x_{r} / \sigma\right)\right]^{r-1}\left[\exp \left(-x_{r} / \sigma\right]^{n-r+1} \frac{1}{\sigma^{2}} .\right.
\end{gathered}
$$

Making the transformation $\mathrm{w}_{\mathrm{s}}=\mathrm{z} / \mathrm{x}_{\mathrm{r}}, \mathrm{x}_{\mathrm{r}}=\mathrm{x}_{\mathrm{r}}$, we find the joint density of $\mathrm{W}_{\mathrm{s}}$ and $\mathrm{X}_{\mathrm{r}}$ as

$$
\begin{gathered}
\mathrm{f}\left(\mathrm{w}_{\mathrm{s}}, \mathrm{x}_{\mathrm{r}} \mid \sigma\right)=\frac{1}{\mathrm{~B}(\mathrm{r}, \mathrm{s}-\mathrm{r}) \mathrm{B}(\mathrm{s}, \mathrm{n}-\mathrm{s}+1)}\left[\exp \left(-\mathrm{w}_{\mathrm{s}} \mathrm{x}_{\mathrm{r}} / \sigma\right)\right]^{\mathrm{n}-\mathrm{s}+1}\left[1-\exp \left(-\mathrm{w}_{\mathrm{s}} \mathrm{x}_{\mathrm{r}} / \sigma\right)\right]^{\mathrm{s}-\mathrm{r}-1} \\
\times\left[1-\exp \left(-\mathrm{x}_{\mathrm{r}} / \sigma\right)\right]^{\mathrm{r}-1}\left[\exp \left(-\mathrm{x}_{\mathrm{r}} / \sigma\right]^{\mathrm{n}-\mathrm{r}+1} \mathrm{x}_{\mathrm{r}} \frac{1}{\sigma^{2}} .\right.
\end{gathered}
$$

It is then straightforward to integrate out $\mathrm{x}_{\mathrm{r}}$, leaving the density of $\mathrm{W}_{\mathrm{s}}$ as

$$
\begin{gathered}
f\left(w_{s}\right)=\frac{1}{B(s-r, n-s+1) B(r, n-r+1)} \sum_{j=0}^{s-r-1} \sum_{i=0}^{r-1}(-1)^{i+j}\left(\begin{array}{c}
s-r-1 \\
j
\end{array}\right)\left(\begin{array}{c}
r-1 \\
i
\end{array}\right) \\
\times \frac{1}{\left[w_{s}(n-s+1+j)+(n-r+1+i)\right]^{2}}, \quad w_{s}>0 .
\end{gathered}
$$

It will be noted that the technique of invariant embedding (Nechval, 1982, 1984, 1986, 1988a, 1988b; Nechval et al., 1999, 2000, 2001, 2003a, 2003b, 2004, 2008, 2009) allows one to obtain (39) directly from (34). This ends the proof. 


\section{Corollary 1.1.}

$$
\begin{gathered}
\operatorname{Pr}\left\{W_{s} \leq w_{s}\right\}=\frac{1}{B(s-r, n-s+1) B(r, n-r+1)} \sum_{j=0}^{s-r-1} \sum_{i=0}^{r-1}(-1)^{i+j}\left(\begin{array}{c}
s-r-1 \\
j
\end{array}\right)\left(\begin{array}{c}
r-1 \\
i
\end{array}\right) \\
\times\left(\frac{1}{n-r+1+i}-\frac{1}{w_{s}(n-s+1+j)+(n-r+1+i)}\right) \frac{1}{(n-s+1+j)} \\
=1-\frac{1}{B(s-r, n-s+1) B(r, n-r+1)} \sum_{j=0}^{s-r-1}(-1)^{j}\left(\begin{array}{c}
s-r-1 \\
j
\end{array}\right)\left[r(n-s+1+j)\left(\begin{array}{c}
w_{s}(n-s+1+j)+n \\
r
\end{array}\right)\right]^{-1} .
\end{gathered}
$$

For a specified probability level $\alpha, w_{s}$ can be obtained such that

$$
\operatorname{Pr}\left\{W_{s} \leq w_{s} \mid X_{r}=x_{r}\right\}=\operatorname{Pr}\left\{\frac{X_{s}-x_{r}}{x_{r}} \leq w_{s}\right\}=\operatorname{Pr}\left\{X_{s} \leq\left(w_{s}+1\right) x_{r}\right\}=\alpha .
$$

Hence, with confidence $\alpha$, one could predict $X_{s}$ to be less than or equal to $\left(w_{s}+1\right) x_{r}$.

Consider, for instance, the case where $n=6$ simultaneously tested items have life times following the exponential distribution (15). Two items $(\mathrm{r}=2)$ fail at times 75 and 90 hours. Suppose, say, we are predicting the 4 th failure time ( $s=4)$. Using (40), (41), and $\alpha=0.95$, we get $\mathrm{w}_{\mathrm{s}}=10$, which yields a predicted value for $X_{\mathrm{s}}$ of 990 hours.

Theorem 2 (Predictive distribution of the sth order statistic $X_{s}$ on the basis of the past observations $X_{1} \leq X_{2} \leq \ldots \leq X_{r}$ from the exponential distribution of the same sample). Under conditions of Theorem 1, the predictive probability density function of the sth order statistic $X_{s}(r<s \leq n)$ may be obtained on the basis of the past observations $\left(X_{1} \leq X_{2} \leq \ldots \leq X_{r}\right)$ from the same sample as

$$
\tilde{f}\left(x_{s} \mid x^{r}\right)=\frac{r}{B(s-r, n-s+1)} \sum_{j=0}^{s-r-1}(-1)^{j}\left(\begin{array}{c}
s-r-1 \\
j
\end{array}\right) \frac{1}{\left[1+w_{s}(n-s+1+j)\right]^{r+1}} \frac{1}{q_{r}}, w_{s}>0,
$$

where

$$
\begin{gathered}
W_{s}=\frac{X_{s}-X_{r}}{Q_{r}}, \\
Q_{r}=\sum_{i=1}^{r} X_{i}+(n-r) X_{r} .
\end{gathered}
$$

Proof. The joint probability density function of $X_{1}, X_{2}, \ldots, X_{r}, X_{s}$ is given by 


$$
\begin{gathered}
f\left(x_{1}, x_{2}, \ldots, x_{r}, x_{s} \mid \sigma\right)=\frac{n !}{(s-r-1) !(n-s) !} \\
\times\left[F\left(x_{s} \mid \sigma\right)-F\left(x_{r} \mid \sigma\right)\right]^{s-r-1}\left[1-F\left(x_{s} \mid \sigma\right)\right]^{n-s} \prod_{i=1}^{r} f\left(x_{i} \mid \sigma\right) f\left(x_{s} \mid \sigma\right) \\
=\frac{n !}{(s-r-1) !(n-s) !} \frac{1}{\sigma^{r+1}} \exp \left(-\frac{\sum_{i=1}^{r} x_{i}+(n-r) x_{r}}{\sigma}\right) \\
\times\left[1-\exp \left(-\frac{x_{s}-x_{r}}{\sigma}\right)\right]^{s-r-1}\left[\exp \left(-\frac{x_{s}-x_{r}}{\sigma}\right)\right]^{n-s+1} .
\end{gathered}
$$

Let

$$
\mathrm{V}=\frac{\mathrm{Q}_{\mathrm{r}}}{\sigma}=\frac{\sum_{\mathrm{i}=1}^{\mathrm{r}} \mathrm{X}_{\mathrm{i}}+(\mathrm{n}-\mathrm{r}) \mathrm{X}_{\mathrm{r}}}{\sigma}
$$

and

$$
W_{s}=\frac{X_{s}-X_{r}}{Q_{r}}=\frac{X_{s}-X_{r}}{\sum_{i=1}^{r} X_{i}+(n-r) X_{r}}
$$

Using the invariant embedding technique (Nechval, 1982, 1984, 1986, 1988a, 1988b; Nechval et al., 1999, 2000, 2001, 2003a, 2003b, 2004, 2008, 2009), we then find in a straightforward manner that the joint density of $V, W_{s}$ conditional on fixed $x^{r}=\left(x_{1}, x_{2}, \ldots, x_{r}\right)$, is

$$
\begin{gathered}
f\left(w_{s}, v \mid x^{r}\right)=\vartheta\left(x^{r}\right) \sum_{j=0}^{s-r-1}\left(\begin{array}{c}
s-r-1 \\
j
\end{array}\right)(-1)^{j} v^{r} \exp \left(-v\left[1+w_{s}(n-s+1+j)\right]\right), \\
w_{s} \in(0, \infty), \quad v \in(0, \infty),
\end{gathered}
$$

where

$$
\vartheta\left(x^{r}\right)=\left(\int_{0}^{\infty} \int_{0}^{\infty} \frac{1}{\vartheta\left(x^{r}\right)} f\left(w_{s}, v \mid x^{r}\right) d w_{s} d v\right)^{-1}=\frac{1}{B(s-r, n-s+1) \Gamma(r)}
$$

is the normalizing constant, which does not depend on $\mathrm{x}^{\mathrm{r}}$. Now $\mathrm{v}$ can be integrated out of (48) in a straightforward way to give 


$$
f\left(w_{s} \mid x^{r}\right)=\frac{r}{B(s-r, n-s+1)} \sum_{j=0}^{s-r-1}\left(\begin{array}{c}
s-r-1 \\
j
\end{array}\right)(-1)^{j} \frac{1}{\left[1+w_{s}(n-s+1+j)\right]^{r+1}}
$$

Then (42) follows from (50). This completes the proof. .

\section{Corollary 2.1.}

$$
\operatorname{Pr}\left\{W_{s} \leq w_{s}\right\}=1-\frac{1}{B(s-r, n-s+1)} \sum_{j=0}^{s-r-1}\left(\begin{array}{c}
s-r-1 \\
j
\end{array}\right)(-1)^{j} \frac{1}{(n-s+1+j)\left[1+w_{s}(n-s+1+j)\right]^{r}}
$$

For a specified probability level $\alpha, \mathrm{w}_{\mathrm{s}}$ can be obtained such that

$$
\operatorname{Pr}\left\{\mathrm{W}_{\mathrm{s}} \leq \mathrm{w}_{\mathrm{s}} \mid \mathrm{X}_{\mathrm{r}}=\mathrm{x}_{\mathrm{r}}, \mathrm{Q}_{\mathrm{r}}=\mathrm{q}_{\mathrm{r}}\right\}=\operatorname{Pr}\left\{\frac{\mathrm{X}_{\mathrm{s}}-\mathrm{x}_{\mathrm{r}}}{\mathrm{q}_{\mathrm{r}}} \leq \mathrm{w}_{\mathrm{s}}\right\}=\operatorname{Pr}\left\{\mathrm{X}_{\mathrm{s}} \leq \mathrm{x}_{\mathrm{r}}+\mathrm{q}_{\mathrm{r}} \mathrm{w}_{\mathrm{s}}\right\}=\alpha .
$$

Hence, with confidence $\alpha$, one could predict $X_{\mathrm{s}}$ to be less than or equal to $\mathrm{x}_{\mathrm{r}}+\mathrm{q}_{\mathrm{r}} \mathrm{w}_{\mathrm{s}}$.

Consider a life-testing situation similar to that in the above example of Theorem 1 , where $n$ $=6$ simultaneously tested items have life times following the exponential distribution (15). Two items $(\mathrm{r}=2)$ fail at times 75 and 90 hours. Suppose, say, we are predicting the 4th failure time ( $\mathrm{s}=4)$. Using (44), (45), (46), and $\alpha=0.95$, we get $\mathrm{q}_{\mathrm{r}}=525$ and $\mathrm{w}_{\mathrm{s}}=1.855$, which yield a predicted value for $X_{s}$ of 1064 hours.

We make two additional remarks concerning evaluation of the above probability (51):

(i) In the important case where $s=n$, expression (51) simplifies to

$$
\operatorname{Pr}\left\{W_{s} \leq w_{s}\right\}=\sum_{j=0}^{n-r}\left(\begin{array}{c}
n-r \\
j
\end{array}\right)(-1)^{j} \frac{1}{\left(1+j w_{s}\right)^{r}}
$$

(ii) In the special case where $r=s-1$, we note that $(s-1)(n-s+1)\left(X_{s}-X_{s-1}\right) / Q_{s-1}$ is an $F$ variate with $(2,2 s-2)$ degrees of freedom, so that appropriate probability statements can be read from standard tables of the $\mathrm{F}$ distribution.

Theorem 3 (Predictive distribution of the sth order statistic $X_{s}$ on the basis of the past order statistics $X_{r}$ and $X_{1}$ from the two-parameter exponential distribution of the same sample). Let $X_{1} \leq X_{2}$ $\leq \ldots \leq X_{\mathrm{r}}$ be the first $\mathrm{r}$ ordered past observations from a sample of size $\mathrm{n}$ from the exponential distribution with the PDF

$$
f(x \mid \sigma)=\frac{1}{\sigma} \exp [-(x-\mu) / \sigma], \quad(\sigma>0,-\infty<\mu<\infty, x \geq \mu),
$$

which is characterized by the scale parameter $\sigma$ and the shift parameter $\mu$. It is assumed that these parameters are unknown. Then the predictive PDF of the sth order statistic $X_{s}(s>r)$ from the same sample may be obtained as

$$
\tilde{f}\left(x_{s} \mid x_{1}, x_{r}\right)=\frac{1}{B(s-r, n-s+1) B(r-1, n-r+1)} \sum_{j=0}^{s-r-1} \sum_{i=0}^{r-2}(-1)^{i+j}\left(\begin{array}{c}
s-r-1 \\
j
\end{array}\right)\left(\begin{array}{c}
r-2 \\
i
\end{array}\right)
$$




$$
\times \frac{1}{\left[w_{s}(n-s+1+j)+(n-r+1+i)\right]^{2}} \frac{1}{x_{r}-x_{1}}, w_{s}>0,
$$

where

$$
\mathrm{W}_{\mathrm{s}}=\frac{\mathrm{X}_{\mathrm{s}}-\mathrm{X}_{\mathrm{r}}}{\mathrm{X}_{\mathrm{r}}-\mathrm{X}_{1}}
$$

Proof. It is carried out in the similar way as the proof of Theorem 1.

\section{Corollary 3.1.}

$$
\begin{gathered}
\operatorname{Pr}\left\{W_{s} \leq w_{s}\right\}=\frac{1}{B(s-r, n-s+1) B(r-1, n-r+1)} \sum_{j=0}^{s-r-1} \sum_{i=0}^{r-2}(-1)^{i+j}\left(\begin{array}{c}
s-r-1 \\
j
\end{array}\right)\left(\begin{array}{c}
r-2 \\
i
\end{array}\right) \\
\quad \times\left(\frac{1}{n-r+1+i}-\frac{1}{w_{s}(n-s+1+j)+(n-r+1+i)}\right) \frac{1}{(n-s+1+j)} \\
=1-\frac{1}{B(s-r, n-s+1) B(r-1, n-r+1)} \sum_{j=0}^{s-r-1}\left(\begin{array}{c}
s-r-1 \\
j
\end{array}\right)(-1)^{j} \frac{[(r-1)(n-s+1+j)]^{-1}}{\left(\begin{array}{c}
w_{s}(n-s+1+j)+n \\
r-1
\end{array}\right)}
\end{gathered}
$$

For a specified probability level $\alpha, \mathrm{w}_{\mathrm{s}}$ can be obtained such that

$$
\begin{gathered}
\operatorname{Pr}\left\{\mathrm{W}_{\mathrm{s}} \leq \mathrm{w}_{\mathrm{s}} \mid \mathrm{X}_{\mathrm{r}}=\mathrm{x}_{\mathrm{r}}, \mathrm{X}_{1}=\mathrm{x}_{1}\right\}=\operatorname{Pr}\left\{\frac{\mathrm{X}_{\mathrm{s}}-\mathrm{x}_{\mathrm{r}}}{\mathrm{x}_{\mathrm{r}}-\mathrm{x}_{1}} \leq \mathrm{w}_{\mathrm{s}}\right\} \\
=\operatorname{Pr}\left\{\mathrm{X}_{\mathrm{s}} \leq \mathrm{x}_{\mathrm{r}}+\mathrm{w}_{\mathrm{s}}\left(\mathrm{x}_{\mathrm{r}}-\mathrm{x}_{1}\right)\right\}=\alpha .
\end{gathered}
$$

Hence, with confidence $\alpha$, one could predict $X_{\mathrm{s}}$ to be less than or equal to $\mathrm{x}_{\mathrm{r}}+\mathrm{w}_{\mathrm{s}}\left(\mathrm{x}_{\mathrm{r}}-\mathrm{x}_{1}\right)$.

Theorem 4 (Predictive distribution of the sth order statistic $X_{s}$ on the basis of the past order statistics $X_{1} \leq X_{2} \leq \ldots \leq X_{r}$ from the two-parameter exponential distribution of the same sample). Under conditions of Theorem 3 , the predictive probability density function of the sth order statistic $X_{s}(s>r)$ from the same sample may be obtained as

$$
\tilde{f}\left(x_{s} \mid x^{r}\right)=\frac{r-1}{B(s-r, n-s+1)} \sum_{j=0}^{s-r-1}\left(\begin{array}{c}
s-r-1 \\
j
\end{array}\right)(-1)^{j} \frac{1}{\left[1+w_{s}(n-s+1+j)\right]^{r}} \frac{1}{q}, \quad w_{s}>0 \text {, }
$$

where

$$
W_{\mathrm{s}}=\frac{X_{\mathrm{s}}-\mathrm{X}_{\mathrm{r}}}{\mathrm{Q}}
$$




$$
Q=\sum_{i=1}^{r}\left(X_{i}-X_{1}\right)+(n-r)\left(X_{r}-X_{1}\right)
$$

Proof. The proof is carried out in the similar way as the proof of Theorem 2 .

\section{Corollary 4.1.}

$$
\begin{aligned}
\operatorname{Pr}\left\{W_{s} \leq\right. & \left.w_{s}\right\}=1-\frac{1}{B(s-r, n-s+1)} \sum_{j=0}^{s-r-1}\left(\begin{array}{c}
s-r-1 \\
j
\end{array}\right)(-1)^{j} \frac{1}{(n-s+1+j)\left[1+w_{s}(n-s+1+j)\right]^{r-1}} \\
& =1-\frac{1}{B(s-r, n-s+1)} \sum_{j=r+1}^{s}\left(\begin{array}{c}
s-r-1 \\
s-j
\end{array}\right)(-1)^{s-j} \frac{1}{(n+1-j)\left[1+w_{s}(n+1-j)\right]^{r-1}} .
\end{aligned}
$$

For a specified probability level $\alpha, \mathrm{w}_{\mathrm{s}}$ can be obtained such that

$$
\operatorname{Pr}\left\{\mathrm{W}_{\mathrm{s}} \leq \mathrm{w}_{\mathrm{s}} \mid \mathrm{X}_{\mathrm{r}}=\mathrm{x}_{\mathrm{r}}, \mathrm{Q}=\mathrm{q}\right\}=\operatorname{Pr}\left\{\frac{\mathrm{X}_{\mathrm{s}}-\mathrm{x}_{\mathrm{r}}}{\mathrm{q}} \leq \mathrm{w}_{\mathrm{s}}\right\}=\operatorname{Pr}\left\{\mathrm{X}_{\mathrm{s}} \leq \mathrm{x}_{\mathrm{r}}+\mathrm{qw}_{\mathrm{s}}\right\}=\alpha .
$$

Hence, with confidence $\alpha$, one could predict $X_{s}$ to be less than or equal to $x_{r}+q_{s}$.

Suppose, for instance, that $n=8$ items are put on test simultaneously and that the first $r=4$ items have the lifetimes 62, 84, 106 and 144 hours. Let the lifetimes of all $\mathrm{n}$ items be distributed according to the two-parameter exponential distribution (47) with the same parameters $\sigma$ and $\mu$. We wish to find a 95\% prediction interval of the type (56) for $s=8$. We obtain from (55) and (56) that $\operatorname{Pr}\left\{\mathrm{X}_{\mathrm{s}} \leq 1408.8\right\}=0.95$. Thus, we can be $95 \%$ confident that the total elapsed time will not exceed 1409 hours.

Theorem 5 (Predictive distribution of the sth order statistic $X_{s}$ on the basis of the past order statistics $X_{1} \leq X_{2} \leq \ldots \leq X_{r}$ from the two-parameter Weibull distribution of the same sample). Let $X_{1}$ $\leq X_{2} \leq \ldots \leq X_{r}$ be the first $r$ ordered past observations from a sample of size $n$ from the twoparameter Weibull distribution given by

$$
f(x \mid \beta, \delta)=\frac{\delta}{\beta}\left(\frac{x}{\beta}\right)^{\delta-1} \exp \left[-\left(\frac{x}{\beta}\right)^{\delta}\right] \quad(x>0)
$$

where $\delta>0$ and $\beta>0$ are the shape and scale parameters, respectively, which are unknown. Then the predictive PDF of the sth order statistic $X_{s}(s>r)$ from the same sample may be obtained as

$$
\tilde{f}\left(x_{s}, v \mid z\right)
$$




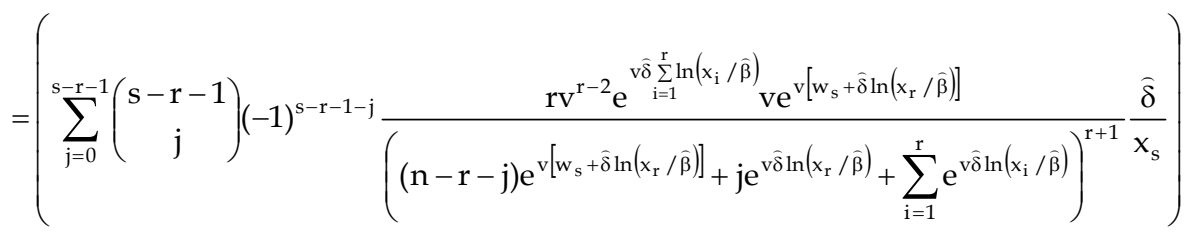

$$
\begin{aligned}
& \times\left(\sum_{j=0}^{s-r-1}\left(\begin{array}{c}
s-r-1 \\
j
\end{array}\right)(-1)^{s-r-1-j} \int_{0}^{\infty} \frac{v^{r-2} e^{v \hat{\delta} \sum_{i=1}^{r} \ln \left(x_{i} / \hat{\beta}\right)}}{(n-r-j)\left(\sum_{i=1}^{r} e^{v \hat{\delta} \ln \left(x_{i} / \hat{\beta}\right)}+(n-r) e^{v \hat{\delta} \ln \left(x_{r} / \hat{\beta}\right)}\right)^{r}} d v\right)^{-1}, \\
& \mathrm{w}_{\mathrm{s}} \in(-\infty, \infty), \quad \mathrm{v} \in(0, \infty) .
\end{aligned}
$$

where $\widehat{\beta}$ and $\widehat{\delta}$ are the maximum likelihood estimators of $\beta$ and $\delta$ based on the first $\mathrm{r}$ ordered past observations $\left(X_{1}, \ldots, X_{r}\right)$ from a sample of size $n$ from the Weibull distribution, which can be found from solution of

$$
\hat{\beta}=\left(\frac{\sum_{i=1}^{r} x_{i}^{\widehat{\delta}}+(n-r) x_{r}^{\hat{\delta}}}{r}\right)^{1 / \hat{\delta}},
$$

and

$$
\begin{gathered}
\widehat{\delta}=\left[\left(\sum_{i=1}^{r} x_{i}^{\hat{\delta}} \ln x_{i}+(n-r) x_{r}^{\hat{\delta}} \ln x_{r}\right)\left(\sum_{i=1}^{r} x_{i}^{\hat{\delta}}+(n-r) x_{r}^{\hat{\delta}}\right)^{-1}-\frac{1}{r} \sum_{i=1}^{r} \ln x_{i}\right]^{-1}, \\
\mathbf{z}=\left(z_{1}, z_{2}, \ldots, z_{r}\right), \\
Z_{i}=\widehat{\delta} \ln \left(\frac{x_{i}}{\hat{\beta}}\right), i=1, \ldots, r \\
W_{s}=\widehat{\delta} \ln \left(\frac{x_{s}}{X_{r}}\right) .
\end{gathered}
$$

Proof. The joint density of $Y_{1}=\ln \left(X_{1}\right), \ldots, Y_{r}=\ln \left(X_{r}\right), Y_{s}=\ln \left(X_{s}\right)$ is given by

$$
\mathrm{f}\left(\mathrm{y}_{1}, \ldots, \mathrm{y}_{\mathrm{r}}, \mathrm{y}_{\mathrm{s}} \mid \mu, \sigma\right)=\frac{\mathrm{n} !}{(\mathrm{s}-\mathrm{r}-1) !(\mathrm{n}-\mathrm{s}) !} \prod_{\mathrm{i}=1}^{\mathrm{r}} \mathrm{f}\left(\mathrm{y}_{\mathrm{i}} \mid \mu, \sigma\right)\left[\mathrm{F}\left(\mathrm{y}_{\mathrm{s}} \mid \mu, \sigma\right)-\mathrm{F}\left(\mathrm{y}_{\mathrm{r}} \mid \mu, \sigma\right)\right]^{\mathrm{s}-\mathrm{r}-1}
$$




$$
\times \mathrm{f}\left(\mathrm{y}_{\mathrm{s}} \mid \mu, \sigma\right)\left[1-\mathrm{F}\left(\mathrm{y}_{\mathrm{s}} \mid \mu, \sigma\right)\right]^{\mathrm{n}-\mathrm{s}},
$$

where

$$
\begin{gathered}
\mathrm{f}(\mathrm{y} \mid \mu, \sigma)=\frac{1}{\sigma} \exp \left[\frac{\mathrm{y}-\mu}{\sigma}-\exp \left(\frac{\mathrm{y}-\mu}{\sigma}\right)\right], \\
\mathrm{F}(\mathrm{y} \mid \mu, \sigma)=1-\exp \left[-\exp \left(\frac{\mathrm{y}-\mu}{\sigma}\right)\right], \\
\mu=\ln \beta, \quad \sigma=1 / \delta .
\end{gathered}
$$

Let $\hat{\mu}, \hat{\sigma}$ be the maximum likelihood estimators (estimates) of $\mu, \sigma$ based on $Y_{1}, \ldots, Y_{r}$ and let

$$
\begin{gathered}
V_{1}=\frac{\hat{\mu}-\mu}{\hat{\sigma}}, \\
V=\frac{\hat{\sigma}}{\sigma}, \\
W_{s}=\frac{Y_{s}-Y_{r}}{\hat{\sigma}},
\end{gathered}
$$

and

$$
Z_{i}=\frac{Y_{i}-\hat{\mu}}{\hat{\sigma}}, i=1(1) r
$$

Parameters $\mu$ and $\sigma$ in (64) are location and scale parameters, respectively, and it is well known that if $\hat{\mu}$ and $\hat{\sigma}$ are estimates of $\mu$ and $\sigma$, possessing certain invariance properties, then the quantities $V_{1}$ and $V$ are parameter-free. Most, if not all, proposed estimates of $\mu$ and $\sigma$ possess the necessary properties; these include the maximum likelihood estimates and various linear estimates. $Z_{i}, i=1(1) r$, are ancillary statistics, any $r-2$ of which form a functionally independent set. For notational convenience we include all of $z_{1}, \ldots, z_{r}$ in (68); $\mathrm{z}_{\mathrm{r}-1}$ and $\mathrm{z}_{\mathrm{r}}$ can be expressed as function of $\mathrm{z}_{1}, \ldots, \mathrm{z}_{\mathrm{r}}$ only.

Using the invariant embedding technique (Nechval, 1982, 1984, 1986, 1988a, 1988b; Nechval et al., 1999, 2000, 2001, 2003a, 2003b, 2004, 2008, 2009), we then find in a straightforward manner that the joint density of $\mathrm{V}_{1}, \mathrm{~V}, \mathrm{~W}_{\mathrm{s}}$ conditional on fixed $\mathbf{z}=\left(z_{1}, z_{2}, \ldots, z_{r}\right)$, is

$$
f\left(w_{s}, v, v_{1} \mid z\right)=\vartheta(z) v^{r-1} \exp \left(v\left[\sum_{i=1}^{r} z_{i}+z_{r}+w_{s}\right]+(r+1) v_{1}\right)
$$




$$
\begin{gathered}
\times \sum_{j=0}^{s-r-1}\left(\begin{array}{c}
s-r-1 \\
j
\end{array}\right)(-1)^{s-r-1-j} \exp \left[-e^{v_{1}}\left((n-r-j) e^{v\left(z_{r}+w_{s}\right)}+j e^{v z_{r}}+\sum_{i=1}^{r} e^{v z_{i}}\right)\right], \\
w_{s} \in(0, \infty), \quad v \in(0, \infty), \quad v_{1} \in(-\infty, \infty),
\end{gathered}
$$

where

$$
\begin{gathered}
\vartheta(\mathbf{z})=\left(\int_{-\infty}^{\infty} \int_{0}^{\infty} \int_{0}^{\infty} \frac{1}{\vartheta(\mathbf{z})} \mathrm{f}\left(\mathrm{w}_{\mathrm{s}}, \mathrm{v}_{1}, \mathrm{v} \mid \mathbf{z}\right) \mathrm{dw_{ \textrm {s } }} d \mathrm{dvdv_{1 }}\right)^{-1} \\
\times\left(\sum_{\mathrm{j}=0}^{\mathrm{s}-\mathrm{r}-1}\left(\begin{array}{c}
\mathrm{s}-\mathrm{r}-1 \\
\mathrm{j}
\end{array}\right)(-1)^{\mathrm{s}-\mathrm{r}-1-\mathrm{j}} \int_{0}^{\infty} \frac{\mathrm{v}^{\mathrm{r}-2} \exp \left(\mathrm{v} \sum_{\mathrm{i}=1}^{\mathrm{r}} \mathrm{z}_{\mathrm{i}}\right)}{(\mathrm{n}-\mathrm{r}-\mathrm{j})\left(\sum_{\mathrm{i}=1}^{\mathrm{r}} \exp \left[v z_{\mathrm{i}}\right]+(\mathrm{n}-\mathrm{r}) \exp \left[v \mathrm{z}_{\mathrm{r}}\right]\right)^{\mathrm{r}}} \mathrm{dv}\right)^{-1}
\end{gathered}
$$

is the normalizing constant.

Now $\mathrm{v}_{1}$ can be integrated out of (79) in a straightforward way to give

$$
\begin{aligned}
& \mathrm{f}\left(\mathrm{w}_{\mathrm{s}}, \mathrm{v} \mid \mathrm{z}\right) \\
& =\left(\sum_{j=0}^{s-r-1}\left(\begin{array}{c}
s-r-1 \\
j
\end{array}\right)(-1)^{s-r-1-j} \frac{r v^{r-2} \exp \left(v \sum_{i=1}^{r} z_{i}\right) v \exp \left[v\left(w_{s}+z_{r}\right)\right]}{\left((n-r-j) \exp \left[v\left(w_{s}+z_{r}\right)\right]+j \exp \left[v z_{r}\right]+\sum_{i=1}^{r} \exp \left[v z_{i}\right]\right)^{r+1}}\right) \\
& \times\left(\sum_{j=0}^{s-r-1}\left(\begin{array}{c}
s-r-1 \\
j
\end{array}\right)(-1)^{s-r-1-j} \int_{0}^{\infty} \frac{v^{r-2} \exp \left(v \sum_{i=1}^{r} z_{i}\right)}{(n-r-j)\left(\sum_{i=1}^{r} \exp \left[v z_{i}\right]+(n-r) \exp \left[v z_{r}\right]\right)^{r}} d v\right)^{-1}
\end{aligned}
$$

Then (65) follows from (81). This completes the proof.

Corollary 5.1. A lower one-sided conditional $(1-\alpha)$ prediction limit $h$ on the sth order statistic $X_{s}(s>r)$ from the same sample may be obtained from (73) as

$$
\operatorname{Pr}\left\{\mathrm{X}_{\mathrm{s}} \geq \mathrm{h} \mid \mathbf{z}\right\}=\operatorname{Pr}\left\{\widehat{\delta} \ln \left(\frac{\mathrm{X}_{\mathrm{s}}}{\widehat{\beta}}\right) \geq \bar{\delta} \ln \left(\frac{\mathrm{h}}{\widehat{\beta}}\right) \mid \mathbf{z}\right\}=\operatorname{Pr}\left\{\mathrm{W}_{\mathrm{s}} \geq \mathrm{w}_{\mathrm{h}} \mid \mathbf{z}\right\}
$$




$$
\begin{aligned}
& =\left(\sum_{j=0}^{s-r-1}\left(\begin{array}{c}
s-r-1 \\
j
\end{array}\right)(-1)^{s-r-1-j} \int_{0}^{\infty} \frac{(n-r-j)^{-1} v^{r-2} e^{v \hat{\delta} \sum_{i=1}^{r} \ln \left(x_{i} / \hat{\beta}\right)}}{\left.(n-r-j) e^{v\left[w_{h}+\hat{\delta} \ln \left(x_{r} / \hat{\beta}\right)\right]}+j e^{v \hat{\delta} \ln \left(x_{r} / \hat{\beta}\right)}+\sum_{i=1}^{r} e^{v \hat{\delta} \ln \left(x_{i} / \hat{\beta}\right)}\right)^{r}} d v\right) \\
& \times\left(\sum_{j=0}^{s-r-1}\left(\begin{array}{c}
s-r-1 \\
j
\end{array}\right)(-1)^{s-r-1-j} \int_{0}^{\infty} \frac{v^{r-2} e^{v \hat{\delta} \sum_{i=1}^{r} \ln \left(x_{i} / \hat{\beta}\right)}}{(n-r-j)\left(\sum_{i=1}^{r} e^{v \hat{\delta} \ln \left(x_{i} / \hat{\beta}\right)}+(n-r) e^{v \hat{\delta} \ln \left(x_{r} / \hat{\beta}\right)}\right)^{r}} d v\right)^{-1} \\
& =1-\alpha \text {. }
\end{aligned}
$$

Let $X_{1} \leq X_{2} \leq \ldots \leq X_{n}$ denote the order statistics in a sample of size $n$ from a continuous parent distribution whose cumulative distribution function $F(x \mid \theta)$ is a strictly increasing function of $x$, where $\theta$ is an unknown parameter. A number of authors have considered the prediction problem for the future observation $X_{s}$ based on the observed values $X_{1} \leq \ldots \leq X_{r}, 1$ $\leq \mathrm{r}<\mathrm{s} \leq \mathrm{n}$. Prediction intervals have been treated by Hewitt (1968), Lawless (1971), Lingappaiah (1973), Likes (1974), and Kaminsky (1977).

Consider, in this section, the case when the parameter $\theta$ is known. It can be shown that the predictive distribution of $X_{n}$, given $X_{i}=x_{i}$ for all $i \leq r$, is the same as the predictive distribution of $X_{n}$, given only $X_{r}=x_{r}$, which is given by

$$
\operatorname{Pr}\left\{\mathrm{X}_{\mathrm{n}} \leq \mathrm{h} \mid \theta, \mathrm{X}_{\mathrm{r}}=\mathrm{x}_{\mathrm{r}}\right\}=\left[\frac{\mathrm{F}(\mathrm{h} \mid \theta)-\mathrm{F}\left(\mathrm{x}_{\mathrm{r}} \mid \theta\right)}{1-\mathrm{F}\left(\mathrm{x}_{\mathrm{r}} \mid \theta\right)}\right]^{\mathrm{n}-\mathrm{r}}
$$

for $h \geq x_{r}$. We remark also at this point that

$$
\operatorname{Pr}\left\{\mathrm{X}_{\mathrm{r}+1} \leq \mathrm{h} \mid \theta, \mathrm{X}_{\mathrm{r}}=\mathrm{x}_{\mathrm{r}}\right\}=1-\left[1-\frac{\mathrm{F}(\mathrm{h} \mid \theta)-\mathrm{F}\left(\mathrm{x}_{\mathrm{r}} \mid \theta\right)}{1-\mathrm{F}\left(\mathrm{x}_{\mathrm{r}} \mid \theta\right)}\right]^{\mathrm{n}-\mathrm{r}}=1-\left[\frac{1-\mathrm{F}(\mathrm{h} \mid \theta)}{1-\mathrm{F}\left(\mathrm{x}_{\mathrm{r}} \mid \theta\right)}\right]^{\mathrm{n}-\mathrm{r}}
$$

for $h \geq x_{r}$.

\subsection{Statistical Inferences for Order Statistics in the Future Sample}

Theorem 6 (Predictive distribution of the lth order statistic $Y_{l}$ from a set of $m$ future ordered observations $Y_{1} \leq \ldots \leq Y_{l} \leq \ldots \leq Y_{m}$ on the basis of the past sample from the left-truncated Weibull distribution). Let $X_{1} \leq X_{2} \leq \ldots \leq X_{r}$ be the first $r$ ordered past observations from a sample of size $\mathrm{n}$ from the left-truncated Weibull distribution with pdf

$$
f(x \mid a, b, \delta)=\frac{\delta}{\sigma} x^{\delta-1} \exp \left[-\left(x^{\delta}-\mu\right) / \sigma\right], \quad\left(x^{\delta} \geq \mu, \sigma, \delta>0\right),
$$


which is characterized by being three-parameter $(\mu, \sigma, \delta)$ where $\delta$ is termed the shape parameter, $\sigma$ is the scale parameter, and $\mu$ is the truncation parameter. It is assumed that the parameter $\delta$ is known. Then the non-unbiased predictive density function of the lth order statistic $Y_{1}$ from a set of $m$ future ordered observations $Y_{1} \leq \ldots \leq Y_{1} \leq \ldots \leq Y_{m}$ is given by

$$
\tilde{f}\left(y_{1} \mid x^{n}\right)= \begin{cases}n(r-1) 1\left(\begin{array}{c}
m \\
1
\end{array}\right) \sum_{i=0}^{1-1} \frac{\left(\begin{array}{c}
1-1 \\
i
\end{array}\right)(-1)^{i}\left[1+w_{l}(m-1+i+1)\right]^{-r}}{n+m-1+i+1} \frac{\delta}{s} y_{l}^{\delta-1}, & \text { if } y_{1} \geq x_{1}, \\
n(r-1) \frac{m !(n+m-1) !}{(m-1) !(n+m) !}\left(1-n_{1}\right)^{-r} \frac{\delta}{s} y_{1}^{\delta-1}, & \text { if } y_{1} \leq x_{1},\end{cases}
$$

where

$$
\begin{gathered}
\mathrm{W}_{\mathrm{l}}=\left(\mathrm{Y}_{1}^{\delta}-\mathrm{X}_{1}^{\delta}\right) / \mathrm{S} \\
\mathrm{S}=\sum_{\mathrm{i}=1}^{\mathrm{r}}\left(\mathrm{X}_{\mathrm{i}}^{\delta}-\mathrm{X}_{1}^{\delta}\right)+(\mathrm{n}-\mathrm{r})\left(\mathrm{X}_{\mathrm{r}}^{\delta}-\mathrm{X}_{1}^{\delta}\right)
\end{gathered}
$$

Proof. It can be justified by using the factorization theorem that $\left(X_{1}^{\delta}, S\right)$ is a sufficient statistic for $(\mu, \sigma)$. We wish, on the basis of the sufficient statistic $\left(X_{1}^{\delta}, S\right)$ for $(\mu, \sigma)$, to construct the non-unbiased predictive density function of the lth order statistic $Y_{1}$ from a set of $\mathrm{m}$ future ordered observations $\mathrm{Y}_{1} \leq \ldots \leq \mathrm{Y}_{1} \leq \ldots \leq \mathrm{Y}_{\mathrm{m}}$.

By using the technique of invariant embedding (Nechval, 1982, 1984, 1986, 1988a, 1988b; Nechval et al., 1999, 2000, 2001, 2003a, 2003b, 2004, 2008, 2009) of $\left(X_{1}^{\delta}, S\right)$, if $X_{1} \leq Y_{1}$, or $\left(Y_{1}^{\delta}, S\right)$, if $X_{1} \geq Y_{1}$, into a pivotal quantity $\left(Y_{1}^{\delta}-\mu\right) / \sigma$ or $\left(X_{1}^{\delta}-\mu\right) / \sigma$, respectively, we obtain an ancillary statistic $\mathrm{W}_{\mathrm{l}}=\left(\mathrm{Y}_{1}^{\delta}-\mathrm{X}_{1}^{\delta}\right) / \mathrm{S}$, whose distribution does not depend on any unknown parameter, and the pdf of $\mathrm{W}_{1}$ given by

$$
f\left(w_{1}\right)= \begin{cases}n(r-1) 1\left(\begin{array}{c}
m \\
1
\end{array} \sum_{i=0}^{1-1} \frac{\left(\begin{array}{c}
1-1 \\
i
\end{array}\right)(-1)^{i}\left[1+w_{1}(m-1+i+1)\right]^{-r}}{n+m-1+i+1},\right. & \text { if } \quad w_{1} \geq 0, \\
n(r-1) \frac{m !(n+m-1) !}{(m-1) !(n+m) !}\left(1-n w_{1}\right)^{-r}, & \text { if } \quad w_{1} \leq 0 .\end{cases}
$$

This ends the proof.

Corollary 6.1. A lower one-sided $(1-\alpha)$ prediction limit $h$ on the lth order statistic $Y_{1}$ from a set of $\mathrm{m}$ future ordered observations $\mathrm{Y}_{1} \leq \ldots \leq \mathrm{Y}_{1} \leq \ldots \leq \mathrm{Y}_{\mathrm{m}}\left(\operatorname{Pr}\left\{\mathrm{Y}_{1} \geq \mathrm{h} \mid \mathrm{x}^{\mathrm{n}}\right\}=1-\alpha\right)$ may be obtained from (89) as 


$$
\mathrm{h}=\left(\mathrm{x}_{1}^{\delta}+\mathrm{w}_{\mathrm{h}} \mathrm{s}\right)^{1 / \delta}
$$

where

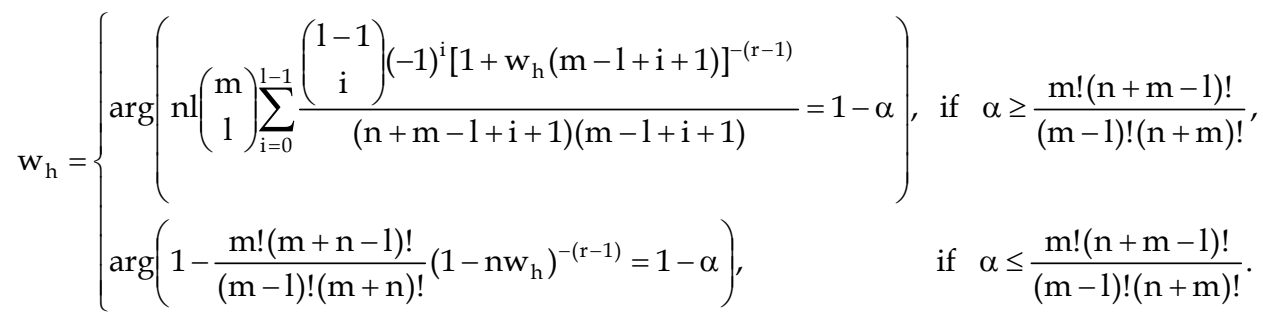

(Observe that an upper one-sided conditional $\alpha$ prediction limit $h$ on the lth order statistic $\mathrm{Y}_{1}$ may be obtained from a lower one-sided (1- $\alpha$ ) prediction limit by replacing $1-\alpha$ by $\alpha$.)

Corollary 6.2. If $l=1$, then a lower one-sided $(1-\alpha)$ prediction limit $h$ on the minimum $Y_{1}$ of a set of $\mathrm{m}$ future ordered observations $\mathrm{Y}_{1} \leq \ldots \leq \mathrm{Y}_{\mathrm{m}}$ is given by

$$
h= \begin{cases}\left(x_{1}^{\delta}+\frac{s}{m}\left[\left(\frac{n}{(1-\alpha)(n+m)}\right)^{\frac{1}{r-1}}-1\right]\right)^{1 / \delta}, & \alpha \geq \frac{m}{n+m}, \\ \left(x_{1}^{\delta}-\frac{s}{n}\left[\left(\frac{m}{\alpha(n+m)}\right)^{\frac{1}{r-1}}-1\right]\right)^{1 / \delta}, & \alpha \leq \frac{m}{n+m} .\end{cases}
$$

Consider, for instance, an industrial firm which has the policy to replace a certain device, used at several locations in its plant, at the end of 24-month intervals. It doesn't want too many of these items to fail before being replaced. Shipments of a lot of devices are made to each of three firms. Each firm selects a random sample of 5 items and accepts his shipment if no failures occur before a specified lifetime has accumulated. The manufacturer wishes to take a random sample and to calculate the lower prediction limit so that all shipments will be accepted with a probability of 0.95 . The resulting lifetimes (rounded off to the nearest month) of an initial sample of size 15 from a population of such devices are given in Table 1 .

\begin{tabular}{ccccccccccccccc}
\hline \multicolumn{11}{c}{ Observations } \\
\hline $\mathrm{x}_{1}$ & $\mathrm{x}_{2}$ & $\mathrm{x}_{3}$ & $\mathrm{x}_{4}$ & $\mathrm{x}_{5}$ & $\mathrm{x}_{6}$ & $\mathrm{x}_{7}$ & $\mathrm{x}_{8}$ & $\mathrm{x}_{9}$ & $\mathrm{x}_{10}$ & $\mathrm{x}_{11}$ & $\mathrm{x}_{12}$ & $\mathrm{x}_{13}$ & $\mathrm{x}_{14}$ & $\mathrm{x}_{15}$ \\
8 & 9 & 10 & 12 & 14 & 17 & 20 & 25 & 29 & 30 & 35 & 40 & 47 & 54 & 62 \\
& \multicolumn{11}{c}{ Lifetime (in number of month intervals) } \\
\hline
\end{tabular}

Table 1. The data of resulting lifetimes 
Goodness-of-fit testing. It is assumed that

$$
X_{i} \sim f(x \mid a, b, \delta)=\frac{\delta}{\sigma} x^{\delta-1} \exp \left[-\left(x^{\delta}-\mu\right) / \sigma\right], \quad(x \geq \mu, \sigma, \delta>0), \quad i=1(1) 15,
$$

where the parameters $\mu$ and $\sigma$ are unknown; $(\delta=0.87)$. Thus, for this example, $r=n=15, k=$ $3, \mathrm{~m}=5,1-\alpha=0.95, X_{1}^{\delta}=6.1$, and $S=170.8$. It can be shown that the

$$
U_{j}=1-\left(\frac{\sum_{i=2}^{j+1}(n-i+1)\left(X_{i}^{\delta}-X_{i-1}^{\delta}\right)}{\sum_{i=2}^{j+2}(n-i+1)\left(X_{i}^{\delta}-X_{i-1}^{\delta}\right)}\right)^{j}, j=1(1) n-2,
$$

are i.i.d. U(0,1) rv's (Nechval et al., 1998). We assess the statistical significance of departures from the left-truncated Weibull model by performing the Kolmogorov-Smirnov goodnessof-fit test. We use the .K statistic (Muller et al., 1979). The rejection region for the $\alpha$ level of significance is $\left\{. \mathrm{K}>\mathrm{K}_{\mathrm{n} ; \alpha}\right\}$. The percentage points for $\mathrm{K}_{\mathrm{n} ; \alpha}$ were given by Muller et al. (1979). For this example,

$$
. \mathrm{K}=0.220<. \mathrm{K}_{\mathrm{n}=13 ; \alpha=0.05}=0.361 \text {. }
$$

Thus, there is not evidence to rule out the left-truncated Weibull model. It follows from (92), for

$$
\alpha=0.05<\frac{\mathrm{km}}{\mathrm{n}+\mathrm{km}}=0.5,
$$

that

$$
\mathrm{h}=\left(\mathrm{x}_{1}^{\delta}-\frac{\mathrm{s}}{\mathrm{n}}\left[\left(\frac{\mathrm{km}}{\alpha(\mathrm{n}+\mathrm{km})}\right)^{\frac{1}{\mathrm{n}-1}}-1\right]\right)^{1 / \delta}=\left(6.1-\frac{170.8}{15}\left[\left(\frac{15}{0.05(15+15)}\right)^{\frac{1}{14}}-1\right]\right)^{1 / 0.87}=5 .
$$

Thus, the manufacturer has $95 \%$ assurance that no failures will occur in each shipment before $\mathrm{h}=5$ month intervals.

\section{Examples}

\subsection{Example 1}

An electronic component is required to pass a performance test of 500 hours. The specification is that 20 randomly selected items shall be placed on test simultaneously, and 5 failures or less shall occur during 500 hours. The cost of performing the test is $\$ 105$ per hour. The cost of redesign is $\$ 5000$. Assume that the failure distribution follows the one-parameter 
exponential model (15). Three failures are observed at 80, 220, and 310 hours. Should the test be continued?

We have from (19) and (20)

$$
\begin{gathered}
\hat{\theta}=\frac{80+220+310+17 \times 310}{3}=1960 \text { hours; } \\
\hat{\mathrm{p}}_{\text {pas }}=\int_{500}^{\infty} \frac{17 !}{2 ! 14 !} \frac{\left[\exp \left(-\frac{310}{1960}\right)-\exp \left(-\frac{\mathrm{x}_{6}}{1960}\right)\right]^{2}}{\left[\exp \left(-\frac{310}{1960}\right)\right]^{17}} \frac{1}{1960}\left[\exp \left(-\frac{\mathrm{x}_{6}}{1960}\right)\right]^{15} \mathrm{dx}_{6}=0.79665 ;
\end{gathered}
$$

Since

$$
\int_{x_{r}}^{\tau_{0}} x_{s} f\left(x_{s} \mid x^{r}, \hat{\sigma}\right) d x_{s}=430.05 \text { hours }>x_{k}+\widehat{p}_{p a s} \frac{c_{2}}{c_{1}}=310+0.79665 \frac{5000}{105}=347.94 \text { hours, }
$$

abandon the present test and initiate a redesign.

\subsection{Example 2}

Consider the following problem. A specification for an automotive hood latch is that, of 30 items placed on test simultaneously, ten or fewer shall fall during 3000 cycles of operation. The cost of performing the test is $\$ 2.50$ per cycle. The cost of redesign is $\$ 8500$. Seven failures, which follow the Weibull distribution with the probability density function (25), are observed at $48,300,315,492,913,1108$, and 1480 cycles. Shall the test be continued beyond the 1480th cycle?

It follows from (29) and (30) that $\hat{\sigma}=2766.6$ and $\bar{\delta}=0.9043$. In turn, these estimates yield $\hat{\mathrm{p}}_{\text {pas }}=0.25098$. Since

$$
\int_{x_{r}}^{\tau_{0}} x_{s} f\left(x_{s} \mid x^{r}, \hat{\sigma}\right) d x_{s}=1877.6 \text { hours }<x_{k}+\widehat{p}_{\text {pas }} \frac{c_{2}}{c_{1}}=1480+0.25098 \frac{8500}{2.5}=2333.33 \text { hours, }
$$

continue the present test.

\section{Stopping Rule in Sequential-Sample Testing}

At the planning stage of a statistical investigation the question of sample size (n) is critical. For such an important issue, there is a surprisingly small amount of published literature. Engineers who conduct reliability tests need to choose the sample size when designing a test plan. The model parameters and quantiles are the typical quantities of interest. The largesample procedure relies on the property that the distribution of the $t$-like quantities is close to the standard normal in large samples. To estimate these quantities the maximum 
likelihood method is often used. The large-sample procedure to obtain the sample size relies on the property that the distribution of the above quantities is close to standard normal in large samples. The normal approximation is only first order accurate in general. When sample size is not large enough or when there is censoring, the normal approximation is not an accurate way to obtain the confidence intervals. Thus sample size determined by such procedure is dubious.

Sampling is both expensive and time consuming. Hence, there are situations where it is more efficient to take samples sequentially, as opposed to all at one time, and to define a stopping rule to terminate the sampling process. The case where the entire sample is drawn at one instance is known as "fixed sampling". The case where samples are taken in successive stages, according to the results obtained from the previous samplings, is known as "sequential sampling".

Taking samples sequentially and assessing their results at each stage allows the possibility of stopping the process and reaching an early decision. If the situation is clearly favorable or unfavorable (for example, if the sample shows that a widget's quality is definitely good or poor), then terminating the process early saves time and resources. Only in the case where the data is ambiguous do we continue sampling. Only then do we require additional information to take a better decision.

In this section, the following optimal stopping rule for determining the efficient sample size sequentially under assigning warranty period is proposed.

\subsection{Stopping Rule on the Basis of the Expected Beneficial Effect}

Suppose the random variables $\mathrm{X}_{1}, \mathrm{X}_{2}, \ldots$, all from the same population, are observed sequentially and follow the two-parameter Weibull fatigue-crack initiation lifetime distribution (64). After the $n$th observation $\left(n \geq n_{0}\right.$, where $n_{0}$ is the initial sample size needful to estimate the unknown parameters of the underlying probability model for the data) the experimenter can stop and receive the beneficial effect on performance,

$$
\mathrm{c}_{1} \mathrm{~h}_{(1: \mathrm{m}) ; \alpha}^{\mathrm{PL}}-\mathrm{cn},
$$

where $c_{1}$ is the unit value of the lower conditional $(1-\alpha)$ prediction limit (warranty period) $\mathrm{h}_{(1: \mathrm{m}) ; \alpha}^{\mathrm{PL}} \equiv \mathrm{h}_{(1: \mathrm{m}) ; \alpha}^{\mathrm{PL}}\left(\mathrm{x}^{\mathrm{n}}\right)$ (Nechval et al., 2007a, 2007b), $\mathrm{x}^{\mathrm{n}}=\left(\mathrm{x}_{1}, \ldots, \mathrm{x}_{\mathrm{n}}\right)$, and $\mathrm{c}$ is the sampling cost.

Below a rule is given to determine if the experimenter should stop in the nth observation, $x_{n}$ or if he should continue until the $(n+1)$ st observation, $X_{n+1}$, at which time he is faced with this decision all over again.

Consider $h_{(1: m) ; \alpha}^{P L}\left(X_{n+1}, x^{n}\right)$ as a function of the random variable $X_{n+1}$, when $x_{1}, \ldots, x_{n}$ are known, then it can be found its expected value

$$
E\left\{h_{(1: m) ; \alpha}^{P L}\left(X_{n+1}, x^{n}\right) \mid x^{n}\right\}=\int_{0}^{\infty} \int_{0}^{\infty} h_{(1: m) ; \alpha}^{P L}\left(x_{n+1}, x^{n}\right) f\left(x_{n+1}, v \mid x^{n}\right) d x_{n+1} d v
$$


where

$$
f\left(x_{n+1}, v \mid x^{n}\right)=\frac{n v^{n-2} e^{v \widehat{\delta} \sum_{i=1}^{n} \ln \left(\frac{x_{i}}{\hat{\beta}}\right)} v e^{v \widehat{\delta} \ln \left(\frac{x_{n}+1}{\hat{\beta}}\right)} \widehat{\delta} x_{n+1}^{-1}}{\int_{0}^{\infty} v^{n-2} e^{v \delta \hat{\delta} \sum_{i=1}^{n} \ln \left(\frac{x_{i}}{\hat{\beta}}\right)}\left(\sum_{i=1}^{n} e^{v \hat{\delta} \ln \left(\frac{x_{i}}{\hat{\beta}}\right)}\right)^{-n} d v}\left(e^{v \hat{\delta} \ln \left(\frac{x_{n+1}}{\hat{\beta}}\right)}+\sum_{i=1}^{n} e^{v \hat{\delta} \ln \left(\frac{x_{i}}{\hat{\beta}}\right)}\right)^{-(n+1)},
$$

the maximum likelihood estimates $\widehat{\beta}$ and $\bar{\delta}$ of $\beta$ and $\delta$, respectively, are determined from the equations (66) and (67), $\int_{0}^{\infty} \mathrm{f}\left(\mathrm{x}_{\mathrm{n}+1}, \mathrm{v} \mid \mathrm{x}^{\mathrm{n}}\right) \mathrm{dv}$ is the predictive probability density function of $X_{n+1}$.

Now the optimal stopping rule is to determine the expected beneficial effect on performance for continuing

$$
c_{1} E\left\{h_{(1: m) ; \alpha}^{P L}\left(X_{n+1}, x^{n}\right) \mid x^{n}\right\}-c(n+1)
$$

and compare this with (102).

If

$$
c_{1}\left(E\left\{h_{(1: m) ; \alpha}^{P L}\left(X_{n+1}, x^{n}\right) \mid x^{n}\right\}-h_{(1: m) ; \alpha}^{P L}\left(x^{n}\right)\right)>c
$$

it is profitable to continue;

If

$$
c_{1}\left(E\left\{h_{(1: m) ; \alpha}^{P L}\left(X_{n+1}, x^{n}\right) \mid x^{n}\right\}-h_{(1: m) ; \alpha}^{P L}\left(x^{n}\right)\right) \leq c,
$$

the experimenter should stop.

\section{Conclusions}

Determining when to stop a statistical test is an important management decision. Several stopping criteria have been proposed, including criteria based on statistical similarity, the probability that the system has a desired reliability, and the expected cost of remaining faults. This paper presents a new stopping rule in fixed-sample testing based on the statistical estimation of total costs involved in the decision to continue beyond an early failure as well as a stopping rule in sequential-sample testing to determine when testing should be stopped.

The paper considers the problem that can be stated as follows. A new product is submitted for lifetime testing. The product will be accepted if a random sample of $n$ items shows less than $\mathrm{s}$ failures in performance testing. We want to know whether to stop the test before it is completed if the results of the early observations are unfavorable. A suitable stopping decision saves the cost of the waiting time for completion. On the other hand, an incorrect stopping decision causes an unnecessary design change and a complete rerun of the test. It 
is assumed that the redesign would improve the product to such an extent that it would definitely be accepted in a new lifetime testing. The paper presents a stopping rule based on the statistical estimation of total costs involved in the decision to continue beyond an early failure. Sampling is both expensive and time consuming. The cost of sampling plays a fundamental role and since there are many practical situations where there is a time cost and an event cost, a sampling cost per observed event and a cost per unit time are both included. Hence, there are situations where it is more efficient to take samples sequentially, as opposed to all at one time, and to define a stopping rule to terminate the sampling process. One of these situations is considered in the paper. The practical applications of the stopping rules are illustrated with examples.

\section{Acknowledgments}

This research was supported in part by Grant No. 06.1936, Grant No. 07.2036, Grant No. 09.1014, and Grant No. 09.1544 from the Latvian Council of Science.

\section{References}

Amster, S. J. (1963). A modified bayes stopping rule. The Annals of Mathematical Statistics, Vol. 34, pp. 1404-1413

Arrow, K. J. ; Blackwell, D. \& Girshick, M. A., (1949). Bayes and minimax solutions of sequential decision problems. Econometrica, Vol. 17, pp. 213-244

El-Sayyad, G. M. \& Freeman, P. R. (1973). Bayesian sequential estimation of a Poisson process rate. Biometrika, Vol. 60, pp. 289-296

Freeman, P. R. (1970). Optimal bayesian sequential estimation of the median effective dose. Biometrika, Vol. 57, pp. 79-89

Freeman, P. R. (1972). Sequential estimation of the size of a population. Biometrika, Vol. 59, pp. $9-17$

Freeman, P. R. (1973). Sequential recapture. Biometrika, Vol. 60, pp. 141-153

Freeman, P. R. (1983). The secretary problem and its extensions: a review. International Statistical Review, Vol. 51, pp. 189-206

Hewitt, J.E. (1968). A note on prediction intervals based on partial observations in certain life test experiments. Technometrics, Vol. 10, pp. 850-853

Kaminsky, K.S. (1977). Comparison of prediction intervals for failure times when life is exponential. Technometrics, Vol. 19, pp. 83-86

Kendall, M. G. \& Stuart, A. S. (1969). The Advanced Theory of Statistics, Vol. 1 (3rd edition), Charles Griffin and Co. Ltd, London

Lawless, J.F. (1971). A prediction problem concerning samples from the exponential distribution with applications in life testing. Technometrics, Vol. 13, pp. 725-730

Likes, J. (1974). Prediction of sth ordered observation for the two-parameter exponential distribution. Technometrics, Vol. 16, pp. 241-244

Lindley, D. V. \& Barnett, B.N. (1965). Sequential sampling: two decision problems with linear losses for binomial and normal random variables. Biometrika, Vol. 52, pp. 507- 532

Lingappaiah, G.S. (1973). Prediction in exponential life testing. Canadian Journal of Statistics, Vol. 1, pp. 113-117 Muller, P.H.; Neumann, P. \& Storm, R. (1979). Tables of Mathematical Statistics, VEB Fachbuchverlag, Leipzig 
Nechval, N. A. (1982). Modern Statistical Methods of Operations Research, RCAEI, Riga

Nechval, N. A. (1984). Theory and Methods of Adaptive Control of Stochastic Processes, RCAEI, Riga

Nechval, N.A. (1986). Effective invariant embedding technique for designing the new or improved statistical procedures of detection and estimation in signal processing systems, In : Signal Processing III: Theories and Applications, Young, I. T. et al. (Eds.), pp. 1051-1054, Elsevier Science Publishers B.V., North-Holland

Nechval, N. A. (1988a). A general method for constructing automated procedures for testing quickest detection of a change in quality control. Computers in Industry, Vol. 10, pp. 177-183

Nechval, N. A. (1988b). A new efficient approach to constructing the minimum risk estimators of state of stochastic systems from the statistical data of small samples, In: Preprint of the 8th IFAC Symposium on Identification and System Parameter Estimation, pp. 71-76, Beijing, P.R. China

Nechval, N.A. \& Nechval, K.N. (1998). Characterization theorems for selecting the type of underlying distribution, In: Proceedings of the $7^{\text {th }}$ Vilnius Conference on Probability Theory and 22nd European Meeting of Statisticians, pp. 352-353, TEV, Vilnius

Nechval, N. A. \& Nechval, K. N. (1999). Invariant embedding technique and its statistical applications, In: Conference Volume of Contributed Papers of the 52nd Session of the International Statistical Institute, Finland, pp. 1-2, ISI - International Statistical Institute, Helsinki, http://www.stat.fi/isi99/proceedings/arkisto/varasto/nech09 02.pdf

Nechval, N. A. \& Nechval, K. N. (2000). State estimation of stochastic systems via invariant embedding technique, In : Cybernetics and Systems'2000, Trappl, R. (Ed.), Vol. 1, pp. 96-101, Austrian Society for Cybernetic Studies, Vienna

Nechval, N. A. ; Nechval, K. N. \& Vasermanis, E. K. (2001). Optimization of interval estimators via invariant embedding technique. IJCAS (An International Journal of Computing Anticipatory Systems), Vol. 9, pp. 241-255

Nechval, K. N. ; Nechval N. A. \& Vasermanis, E. K. (2003a). Adaptive dual control in one biomedical problem. Kybernetes (The International Journal of Systems \& Cybernetics), Vol. 32, pp. 658-665

Nechval, N. A. ; Nechval, K. N. \& Vasermanis, E. K. (2003b). Effective state estimation of stochastic systems. Kybernetes (The International Journal of Systems \& Cybernetics), Vol. 32, pp. 666-678

Nechval, N. A. \& Vasermanis, E. K. (2004). Improved Decisions in Statistics, SIA "Izglitibas soli", Riga

Nechval, K. N. ; Nechval, N. A. ; Berzins, G. \& Purgailis, M. (2007a). Planning inspections in service of fatigue-sensitive aircraft structure components for initial crack detection. Maintenance and Reliability, Vol. 35, pp. 76-80

Nechval, K. N. ; Nechval, N. A. ; Berzins, G. \& Purgailis, M. (2007b). Planning inspections in service of fatigue-sensitive aircraft structure components under crack propagation. Maintenance and Reliability, Vol. 36, pp. 3-8

Nechval, N. A. ; Berzins, G. ; Purgailis, M. \& Nechval, K. N. (2008). Improved estimation of state of stochastic systems via invariant embedding technique. WSEAS Transactions on Mathematics, Vol. 7, pp. 141-159 
Nechval, N. A. ; Berzins, G. ; Purgailis, M. ; Nechval, K .N. \& Zolova, N. (2009). Improved adaptive control of stochastic systems. Advances In Systems Science and Applications, Vol. 9, pp. 11-20

Petrucelli, J. D. (1988) Secretary Problem, In : Encyclopedia of Statistical Sciences, Kotz, S. \& Johnson, N. (Eds.), Vol. 8, pp. 326-329, Wiley, New York

Raiffa, H. \& Schlaifer, R. (1968). Applied Statistical Decision Theory, Institute of Technology Press, Massachusetts

Samuels, S. M. (1991). Secretary Problems, In : Handbook of Sequential Analysis, Ghosh, B. K. \& Sen, P. K. (Eds.), pp. 35-60, Dekker, New York

Wald, A. \& Wolfowitz, J. (1948). Optimum character of the sequential probability ratio test. The Annals of Mathematical Statistics, Vol. 19, pp. 326-339 


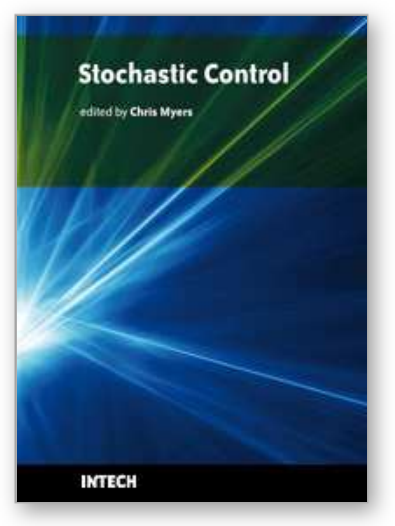

\author{
Stochastic Control \\ Edited by Chris Myers
}

ISBN 978-953-307-121-3

Hard cover, 650 pages

Publisher Sciyo

Published online 17, August, 2010

Published in print edition August, 2010

Uncertainty presents significant challenges in the reasoning about and controlling of complex dynamical systems. To address this challenge, numerous researchers are developing improved methods for stochastic analysis. This book presents a diverse collection of some of the latest research in this important area. In particular, this book gives an overview of some of the theoretical methods and tools for stochastic analysis, and it presents the applications of these methods to problems in systems theory, science, and economics.

\title{
How to reference
}

In order to correctly reference this scholarly work, feel free to copy and paste the following:

Nicholas A. Nechval and Maris Purgailis (2010). Stochastic Decision Support Models and Optimal Stopping Rules in a New Product Lifetime Testing, Stochastic Control, Chris Myers (Ed.), ISBN: 978-953-307-121-3, InTech, Available from: http://www.intechopen.com/books/stochastic-control/stochastic-decision-supportmodels-and-optimal-stopping-rules-in-a-new-product-lifetime-testing-

\section{INTECH}

open science | open minds

\section{InTech Europe}

University Campus STeP Ri

Slavka Krautzeka 83/A

51000 Rijeka, Croatia

Phone: +385 (51) 770447

Fax: +385 (51) 686166

www.intechopen.com

\section{InTech China}

Unit 405, Office Block, Hotel Equatorial Shanghai

No.65, Yan An Road (West), Shanghai, 200040, China

中国上海市延安西路65号上海国际贵都大饭店办公楼 405 单元

Phone: +86-21-62489820

Fax: $+86-21-62489821$ 
(C) 2010 The Author(s). Licensee IntechOpen. This chapter is distributed under the terms of the Creative Commons Attribution-NonCommercialShareAlike-3.0 License, which permits use, distribution and reproduction for non-commercial purposes, provided the original is properly cited and derivative works building on this content are distributed under the same license. 